Chapman University

Chapman University Digital Commons

Mathematics, Physics, and Computer Science

Science and Technology Faculty Articles and

Faculty Articles and Research

Research

2012

\title{
Impact of Vegetation on Land-Atmosphere Coupling Strength and Its Implication for Desertification Mitigation over East Asia
}

Boksoon Myoung

Chapman University, bmyoung@chapman.edu

Yong-Sang Choi

Ewha Womans University

Suk-Jin Choi

Ewha Womans University

Seon Ki Park

Ewha Women's University

Follow this and additional works at: http://digitalcommons.chapman.edu/scs_articles

Part of the Atmospheric Sciences Commons, Climate Commons, Desert Ecology Commons, Earth Sciences Commons, Environmental Monitoring Commons, and the Other Forestry and Forest $\underline{\text { Sciences Commons }}$

\section{Recommended Citation}

Myoung, B., Y.-S. Choi, S.-J. Choi, and S. K. Park (2012), Impact of vegetation on land-atmosphere coupling strength and its implication for desertification mitigation over East Asia, J. Geophys. Res., 117, D12113, doi:10.1029/2011JD017143.

This Article is brought to you for free and open access by the Science and Technology Faculty Articles and Research at Chapman University Digital Commons. It has been accepted for inclusion in Mathematics, Physics, and Computer Science Faculty Articles and Research by an authorized administrator of Chapman University Digital Commons. For more information, please contact laughtin@chapman.edu. 


\section{Impact of Vegetation on Land-Atmosphere Coupling Strength and Its Implication for Desertification Mitigation over East Asia}

\section{Comments}

This article was originally published in Journal of Geophysical Research, volume 117, in 2012. DOI: 10.1029/ 2011JD017143

\section{Copyright}

American Geophysical Union 


\title{
Impact of vegetation on land-atmosphere coupling strength and its implication for desertification mitigation over East Asia
}

\author{
Boksoon Myoung, ${ }^{1}$ Yong-Sang Choi, ${ }^{1,2,3}$ Suk-Jin Choi, ${ }^{4}$ and Seon Ki Park ${ }^{1,2,3}$ \\ Received 10 November 2011; revised 5 April 2012; accepted 10 May 2012; published 29 June 2012.
}

[1] Desertification of the East Asian drylands and the consequent dust transport have been serious concerns for adjacent Asian countries as well as the western United States. Tree planting has been considered one applicable strategy to mitigate the desertification. However, the desired effect of the tree planting would not be brought to fruition unless the newly planted trees change the coupling characteristics between the land and the atmosphere. Based on this perception, we attempt to clarify the effects of vegetation on the coupling strength between the atmosphere and land surface, and we suggest the most efficient areas of tree planting for desertification mitigation in East Asia. Using regional vegetation-atmosphere coupled model simulations, coupling strength with and without vegetation was computed and compared with each other. An increased vegetation fraction reduces the coupling strength in June, July, and August (JJA), primarily due to decreased evapotranspiration variability. This effect is pronounced over the Manchurian Plains and the highly populated areas of Beijing and Tianjin. The reduced coupling strength tends to weaken feedback between soil moisture and precipitation as a maintenance mechanism of warm season droughts in the midlatitudes and subsequently decrease the probability of droughts, a finding that is reflected in the enhanced JJA mean soil moisture. However, some drylands like the eastern edges of the Gobi desert present marginal or even opposite changes in coupling strength, meaning a limited effect of vegetation on relieving droughts.

Therefore, given limited financial and human resources, acupuncture-like afforestation, i.e., concentrated tree planting in a particular region where the coupling strength can be substantially reduced by vegetation, is an effective strategy to secure long-standing desertification mitigation.

Citation: Myoung, B., Y.-S. Choi, S.-J. Choi, and S. K. Park (2012), Impact of vegetation on land-atmosphere coupling strength and its implication for desertification mitigation over East Asia, J. Geophys. Res., 117, D12113, doi:10.1029/2011JD017143.

\section{Introduction}

[2] United Nations Convention to Combat Desertification (UNCCD) [2004] defines desertification as land degradation in the drylands (e.g., arid, semiarid and dry subhumid areas), caused by various factors including natural climatic variations and human intervention. Deserts in Gobi and Taklamakan in Mongolia and in northwestern China across East Asia have expanded substantially over the past several

\footnotetext{
${ }^{1}$ Center for Climate/Environment Change Prediction Research, Ewha Womans University, Seoul, South Korea.

${ }^{2}$ Severe Storm Research Center, Ewha Womans University, Seoul, South Korea.

${ }^{3}$ Department of Environmental Science and Engineering, Ewha Womans University, Seoul, South Korea.

${ }^{4}$ Korea Institute of Atmospheric Prediction Systems, Seoul, South Korea.

Corresponding author: Y.-S. Choi, Department of Environmental Science and Engineering, Ewha Womans University, New Engineering Bldg. 105-3, Daehyun-Dong, Seodaemoon-Gu, Seoul 120-750, South Korea. (ysc@ewha.ac.kr)

C2012. American Geophysical Union. All Rights Reserved. 0148-0227/12/2011JD017143
}

decades [Yu et al., 2004; Lin et al., 2009; Jeong et al., $2011 \mathrm{~b}$ ]. The socioeconomic and health impacts of the desertification, and consequent transboundary transports of enormous yellow sands originating from those regions are serious concerns not only for China and the adjacent countries in East Asia but also for the western U.S. [Husar et al., 2001; Zhang et al., 2003], so that desertification mitigation has been a vital environmental issue across these regions. In order to mitigate the desertification, many efforts have been made such as tree planting, windbreak building, petroleum spraying, and artificial precipitation formation. These methods are likely to have various effects on the local surface and soil characteristics and microclimate through physical changes (e.g., decreased wind speeds, soil erosion, and runoff) and/or thermodynamic changes (e.g., changes in surface energy and water balance).

[3] However, it remains equivocal that these efforts have substantial effects on desertification mitigation, inducing satisfactory consequences via the change of land-atmosphere coupling (e.g., feedback between precipitation and soil moisture or surface temperature) that is a major cause of 
droughts and desertification in subtropics and midlatitudes. Unfortunately, such a land-atmosphere coupling cannot readily be changed by land surface changes if the feedback is dominated by dynamic circulations. Therefore, one should pay more attention to a longer-standing solution, i.e., the changes in hydrological coupling strength between the atmosphere and the land surface changes.

[4] The strong land-atmosphere coupling implies strong dependency of local climates on lands and high vulnerability of the drylands to warm season (April-September) droughts [Koster et al., 2004, 2006; Seneviratne et al., 2006]. This is because the coupling over the drylands is primarily driven by a positive feedback between precipitation and soil moisture (i.e., precipitation deficit and dry soil) and because initial abrupt precipitation deficits are more likely to develop into droughts through this feedback. It has been found that, while warm season droughts tend to be initiated by a precipitation deficit caused by anomalous large-scale circulations, they are maintained through the positive feedback between the soil moisture and the precipitation over the central U.S. [Namias, 1982; Trenberth et al., 1988; Hong and Kalnay, 2002; Sud et al., 2003]. This mechanism may also be favorable in the drylands over Mongolia and northern China, with strong hydrological coupling between local precipitation and soil moisture [Koster et al., 2006; Wang et al., 2007; Zeng et al., 2010]. Over these regions, over $60 \%$ of the annual precipitation is concentrated on summer [Yang and Lau, 2004]. Thus, rainfall suppression during the warm seasons could easily develop into serious long-term droughts. For this reason, the coupling strength and its change are particularly sensitive to vulnerability to droughts and, consequently, desertification.

[5] Vegetation can modify the coupling strength mainly by changing its evapotranspiration rate, surface energy flux, surface albedo and surface roughness length [Foley, 1994; Pielke et al., 1998; Prentice et al., 2000; Jeong et al., 2009, 2011a]. For example, use of the Community Land Model (CLM) revealed that an increased rate of rain dropping from leaves to the ground was found to enhance the coupling strength over the U.S. [Wang et al., 2007]. However, dozens of parameters are associated with vegetation in the CLM, and the vegetation effect on the coupling strength is largely dependent on regional characteristics of soil, vegetation type, local climate, and topography. Accordingly, the integrated impact of vegetation on coupling strength in drylands is worth investigation.

[6] Although the coupling strength in East Asian drylands has not yet been investigated, several studies found the climatic impact of vegetation worldwide in various aspects: contributions of forests in the midlatitude to global circulations [e.g., Bonan et al., 1992; Rotenberg and Yakir, 2010; Swann et al., 2012], contributions of vegetation to monsoonal circulations in southeastern Asia [e.g., Xue, 1996; Sen et al., 2004; Xue et al., 2004], the impacts of afforestation in the Sahel and Amazon regions of the tropics in terms of the changes in surface energy balance, ground and undergroundwater flow, atmospheric water and precipitation, and surface temperature [Jackson et al., 2000; Koster et al., 2004; Farley et al., 2005]. We note that the impacts of deforestation on climate and water supplies have been also studied extensively [Henderson-Sellers et al., 1993; Xue and Shukla, 1993; Sahin and Hall, 1996], but the hydrological and thermodynamic influences of deforestation may not be the exact opposite to those of afforestation.

[7] The vegetation effect on modulating the coupling strength has implication of afforestation policy to mitigate desertification. To use a metaphor, this effect of afforestation may be compared with oriental herb treatment that aims to cure the root causes of disease and improve the physical constitution of the human body rather than focus on removing disease symptoms. Additionally, if the modulation of the coupling strength occurs not remotely but locally, identifying a region with maximal vegetation-induced changes in coupling strength will be of great use to policy makers because they can determine the most effective tree planting regions. This is indeed important for those with limited economic and human resources. In this regard, this concentrated tree planting is what we refer to as "acupuncture-like afforestation." Based on the aforementioned rationale, we first investigates the impact of vegetation on the land-atmosphere coupling over the entire study region in East Asia. Then we will suggest the tree planting with due consideration of the land-atmosphere coupling for desertification mitigation within the study region.

\section{Experiment Design and Computation of Coupling Strength}

[8] This study is based on the coupled model simulation: the regional climate model (Weather Research Forecasting model 3.0; WRF) coupled with the land surface model (CLM model 3.5) from University of California at Berkeley is employed with $6 \mathrm{~h}$ NCEP final analysis (FNL) data for initial and boundary conditions. In this model, the land soil is represented by 17 soil texture types, which determine the thermal and hydrologic soil properties. The terrestrial vegetation is described by 16 Plantation Functional Types (PFTs). The land use data set of USGS provided by the WRF preprocessing system was used, which allowed for 24 land use categories that are determined by the combination of bare ground and several PFT types. Vegetation phenology is provided from the vegetation fraction of the monthly averaged USGS data. The PFTs characterize properties including solar radiation, soil root distribution, aerodynamics at the vegetation-atmosphere interface, and photosynthesis rates [Oleson et al., 2004]. The spatial distributions of the most and second dominant PFTs within the domain of the study are shown in Figures 1a and 1b, respectively, with the summer (June, July, and August, or JJA) mean vegetation fraction shown in Figure 1c. Figure 1 also displays four subregions of interest: the eastern edges of the Gobi desert in the north central domain (NC), the Manchurian Plains in northeastern China (NE), the urban areas (Beijing and Tianjin) of central China (UC), and the crop regions of south central China (SC). The region, SC, is included due to substantial changes in coupling strength as shown later in this manuscript, though having a subtropical climate. A short summary on the local climate and major vegetation types in each selected region is listed in Table 1.

[9] The model domain has $141 \times 141$ grid points with a horizontal grid spacing of $30 \mathrm{~km}$. The physical parameterization schemes used in this study are the Kain-Fritsch convective parameterization scheme, WSM3 cloud microphysics scheme, RRTM long-wave radiation scheme, MM5 

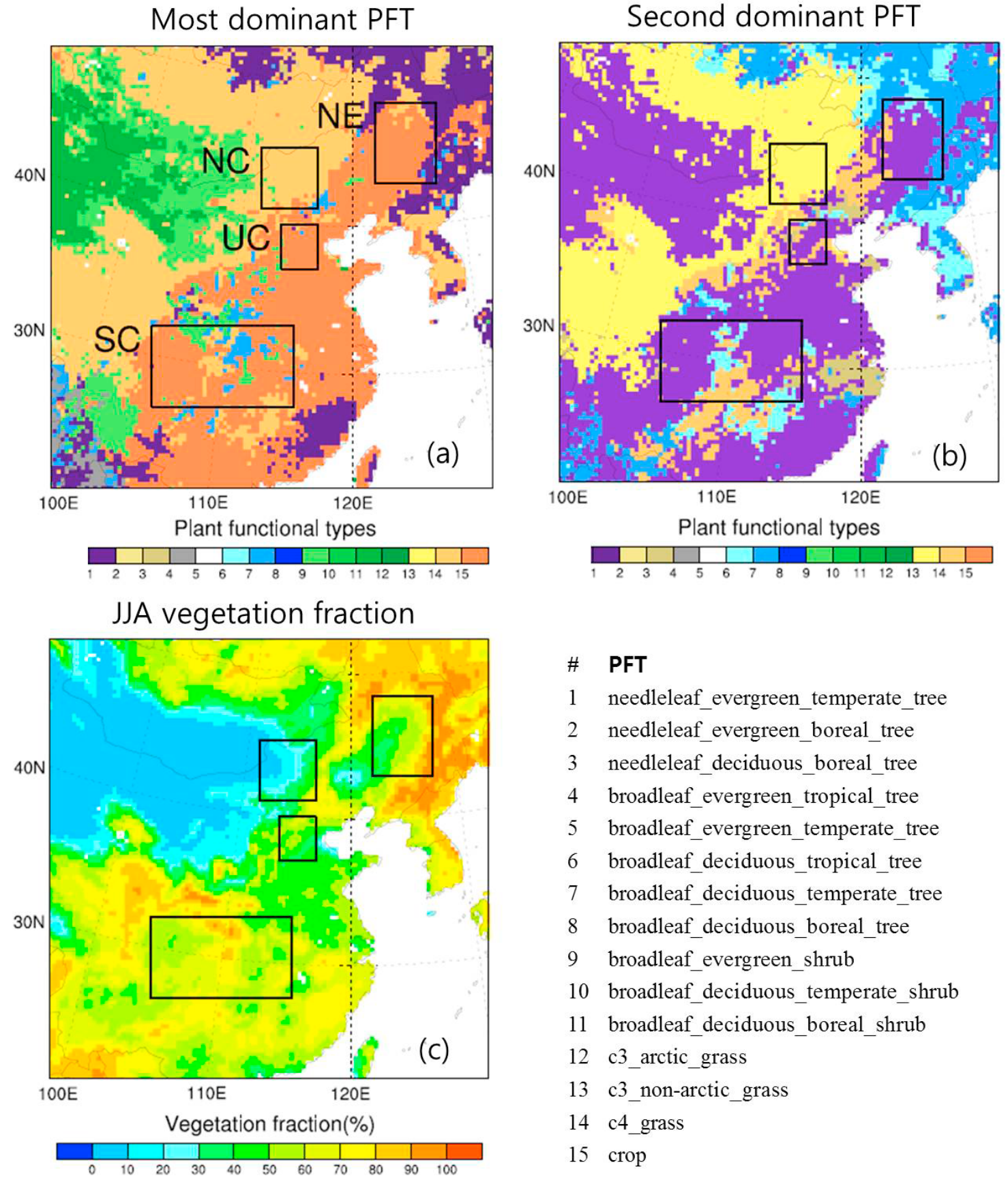

Figure 1. Research domain of four subregions of interest (NC, NE, UC, and SC) indicated by rectangular boxes. Most and second dominant PFTs in the domain are shown in Figures 1a and 1b, respectively, with JJA mean vegetation fraction (\%) in Figure 1c.

Table 1. Climate and Dominant Plantation Functional Types (PFTs) of the Four Subregions ${ }^{\mathrm{a}}$

\begin{tabular}{lcccc}
\hline & NC & NE & UC & SC \\
\hline Climate & Semiarid & Between semiarid and temperate monsoon & Temperate monsoon & Subtropical monsoon \\
First dominant PFT & Grass (C4) & Crop & Crop & Crop \\
Second dominant PFT & Grass (nonarctic C3) & NETT & NETT & NETT \\
\hline
\end{tabular}

${ }^{\mathrm{a}}$ NETT indicates needleleaf evergreen temperate tree. 
long-wave radiation scheme, and YSU planetary boundary layer scheme. This study employs two different experiments: CLM default prescribed vegetation (VEG experiment) and bare ground (NOVEG experiment). While, in the VEG experiment, each grid is assigned by both bare ground and several PFTs up to four, all the PFTs in a grid was set to zero (i.e., bare ground) in the NOVEG experiment. Once calculations are performed at the PFT level in the CLM, fluxes of energy, water, and momentum are aggregated at the grid cell level and passed to the WRF. The WRF provides atmospheric components such as wind, temperature, humidity, pressure, and number of radiations at the lowest level to the CLM. The CLM then calculates surface energy, albedo, momentum, and radiation fluxes and updates the soil hydrologic states based on these fluxes, which are then passed back to the WRF. The simulation period was from 1 January 2000 to 31 December 2004. Output data from 1 January to 30 November 2000 are discarded as a spin-up period; in the rest, 4 year outputs were used for the analysis.

[10] To investigate the effects of vegetation on hydrological land-atmospheric coupling, this study focuses on monthly anomalies of precipitation $\left(P^{\prime}\right)$ and evapotranspiration $\left(E^{\prime}\right)$ and coupling strength (CS). Based on the study of Zeng et al. [2010], the hydrological CS is calculated using the equation as follows:

$$
C S=\frac{\sum_{i=1}^{N} P_{i}^{\prime} \cdot E_{i}^{\prime}}{\sum_{i=1}^{N} P_{i}^{\prime 2}}
$$

[11] Here, $i$ is the number of months; $P^{\prime}$ is the 30 day anomaly of precipitation $(\mathrm{mm} / \mathrm{d})$ with a 5 day moving interval; and $E^{\prime}$ is the 30 day anomaly of evapotranspiration $(\mathrm{mm} / \mathrm{d})$ with a 5 day moving interval. The anomalies $P^{\prime}$ and $E^{\prime}$ are computed based on 4 year averages of monthly (i.e., 30 day) precipitation and evapotranspiration, respectively. The total number of months $(N)$ is 52 (13 cases $\times 4$ years) (e.g., 1-30 June, 5 June to 4 July, 10 June to 9 July, 1-30 August). The CS estimates the fractional contribution of the covariance between precipitation and evapotranspiration deviations to variance of the precipitation deviations. The greater contribution of $E^{\prime}$ to $P^{\prime}$, and vice versa, for the same variance of $P^{\prime}$ leads to a higher CS. The analysis was performed only for JJA and for regions with rainfall $\geq 1.5 \mathrm{~mm} / \mathrm{d}$ in this study. This is because the impacts of vegetation are the most pronounced in the summer and because CS computation is meaningless over regions with extremely low rainfall rates, which is the case over the most northern domains in the other seasons.

\section{Results}

\subsection{Impact of Vegetation on Mean and Variability of Hydrological Variables}

[12] Figure 2 shows JJA mean precipitation $(\bar{P})$ and evapotranspiration $(\bar{E})$ of the VEG experiment for 20012004 and their differences $(\Delta)$ between the VEG and NOVEG experiments $(\Delta \bar{P}$ and $\Delta \bar{E})$. In general, the WRFCLM model simulates well 4 year summer climatology of $P$ and $E$ over most of East Asia (Figures $2 \mathrm{a}$ and 2c), both in the magnitude and geographical distribution, compared with observations (not shown). For both $\bar{P}$ and $\bar{E}$, strong gradients between the northwestern and southeastern regions are also found in observations. The model has a tendency to overestimate rainfall along the southern boundary of the domain (Figure 2a). Despite some heterogeneous spatial patterns, vegetation tends to increase both precipitation and evapotranspiration over the northwestern regions, but to decrease them over the southern regions (Figures $2 \mathrm{~b}$ and $2 \mathrm{~d}$ ), consequently diminishing the northwest-southeast gradients. These differences between VEG and NOVEG are statistically significant over most of the model domain at a $95 \%$ confidence level.

[13] On the other hand, changes in $\bar{P}$ and $\bar{E}$ are expected to contribute to changes in soil moisture in a transition zone between dry and humid regions; namely, higher $\bar{P}-\bar{E}$ is likely to induce wetter soil. Figure 3 displays $\bar{P}-\bar{E}$ (Figure 3a) and soil moisture differences in the top $1.8 \mathrm{~cm}$ layer $(\overline{S M})$ (Figure $3 \mathrm{~b}$ ). Comparison of Figure $3 \mathrm{a}$ with $3 \mathrm{~b}$ indicates that spatial patterns of the difference of $\bar{P}-\bar{E}$ are not identical to those of $\overline{S M}$, while extremely high $\bar{P}-\bar{E}$ is responsible for the increase of $\overline{S M}$ in some regions (e.g., the eastern part of NE and the areas between UC and SC). This result suggests that soil moisture changes associated with changes in vegetation are only partly controlled by mean changes in $\bar{P}-\bar{E}$.

[14] The impact of vegetation is also present upon variability of $P$ and $E$, which is illustrated in Figure 4 showing standard deviations of monthly $P^{\prime}$ and $E^{\prime}\left(\sigma\left(P^{\prime}\right)\right.$, and $\left.\sigma\left(E^{\prime}\right)\right)$ and their differences $\left(\Delta \sigma\left(P^{\prime}\right)\right.$, and $\left.\Delta \sigma\left(E^{\prime}\right)\right)$ between the VEG and NOVEG experiments. As to precipitation, $\sigma\left(P^{\prime}\right)$ is similar to $\bar{P}$ in terms of a northwest-southeast gradient (Figures 2a and 4a). However, as to evapotranspiration, the similarity between $\sigma\left(E^{\prime}\right)$ and $\bar{E}$ is unclear (Figures 2c and 4c). Spatial patterns of $\Delta \sigma\left(P^{\prime}\right)$ (Figure $4 \mathrm{~b}$ ) are rather distinct from those of $\Delta \bar{P}$, especially over the Gobi desert in the northwestern regions of the domain (Figure 2b). Discrepancy in the vegetation-induced differences between the mean and the variance of evapotranspiration (Figures $2 \mathrm{~d}$ and $4 \mathrm{~d}$ ) is noticeable mainly in the Gobi desert and the central China. The values $\Delta \sigma\left(E^{\prime}\right)$ appear to be statistically significant over the four sub study regions at the $95 \%$ level (Figure $4 \mathrm{~d}$ ), while the values $\Delta \sigma\left(P^{\prime}\right)$ are less significant (Figure 4b). These characteristics indicate that vegetation affects both mean and variability of precipitation and evapotranspiration, but with different sensitivity to regions. A significant amount of literature investigating the response of precipitation to the changes in vegetation discussed in the review paper of Pielke et al. [2007] mostly tackled issues associated with the mean changes in precipitation. In this study, we focus on the variability rather than the mean of the hydrological variables because CS is dependent on their anomalies only, as defined in equation (1).

\subsection{Modulation of Vegetation on Coupling Strength}

[15] The CS of the VEG and NOVEG experiments in JJA and the differences between the VEG and NOVEG experiments are displayed in Figure 5. Although CS in Figure 5a is based on the model output of WRF-CLM, the spatial pattern and magnitudes of CS are very similar to the coupling strength computed by ECMWF reanalysis in Zeng et al. [2010, Figure 1] despite both analyses in different time periods and different data resolutions. While CS is higher 
(a) VEG experiment
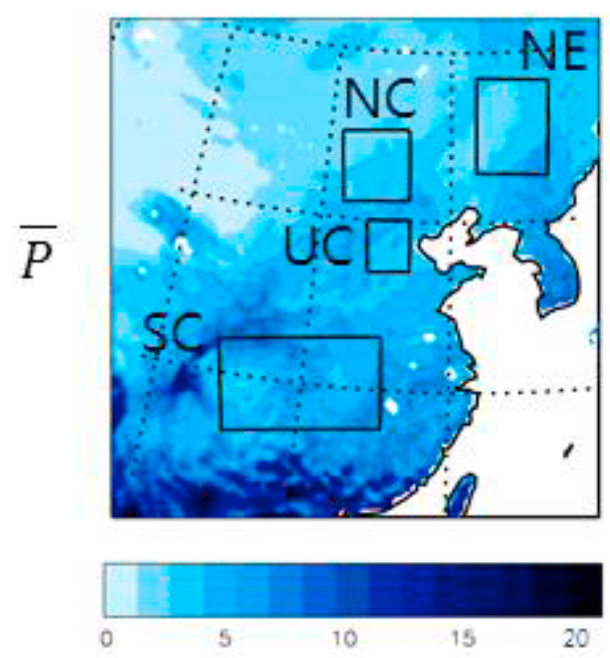

\section{(c) VEG experiment}


(b) VEG minus NOVEG (significant area only)
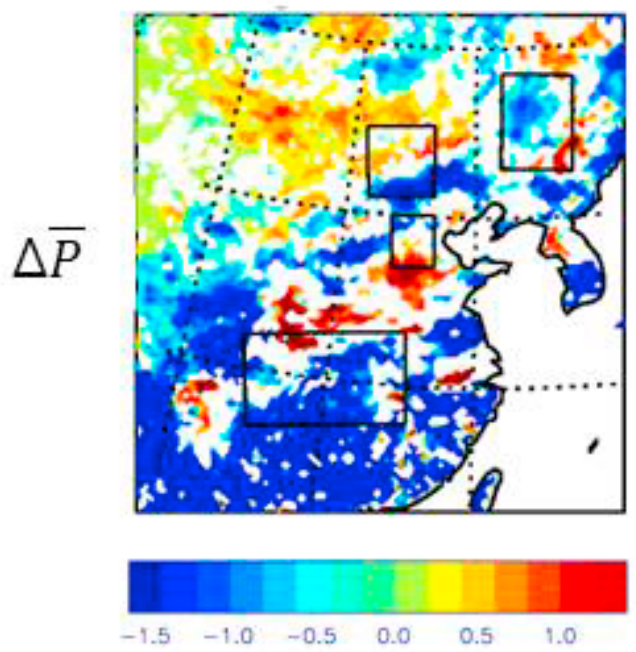

(d) VEG minus NOVEG (significant area only)
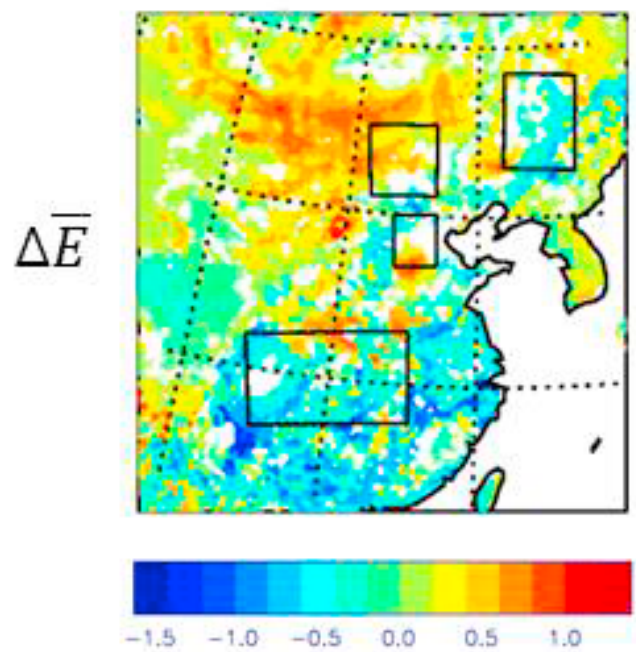

Figure 2. (a) JJA mean precipitation in VEG and (b) its difference between VEG and NOVEG (areas significantly different at a $95 \%$ confidence level). (c and d) The same as in Figures $2 \mathrm{a}$ and $2 \mathrm{~b}$ but for evapotranspiration. Units are $\mathrm{mm} / \mathrm{d}$.

over the northern domain than the southern domain because of the limited availability of soil moisture (Figure 5a), VEG had a lower CS than did NOVEG in most of the domain (Figure 5c). Over the three selected areas (NE, UC, and SC) in particular, the reduction rate of CS by inclusion of vegetation ranged from $40 \%$ to $85 \%$ (Table 2). In contrast, a higher CS was identified over the eastern edges of the Gobi desert (NC) (18\% increase; Table 2). A student's $t$ test for the difference of CSs computed for each summer of 20012004 ( $p$ value in Table 2) indicates that the differences in the negative regions (NE, UC, and SC) are statistically significant at the $95 \%$ level. The opposite response of CS to vegetation is partially attributed to the characteristics of the present major vegetation types (i.e., crop and needleleaf evergreen temperate tree (NETT) in NE, UC, and SC versus grass in $\mathrm{NC}$ as shown in Figures $1 \mathrm{a}$ and $1 \mathrm{~b}$ and in Table 1) since the combination of crop/grass as the first/second PFTs in Figures 1a and 1b (e.g., the southwestern NE and UC neighborhoods and the south central SC) tends to hamper the reduction of CS compared to the combination of crop/NETT (e.g., the central NE and UC and the eastern SC). Moreover, replacing the grass with crops in $\mathrm{NC}$ in an additional experiment resulted in negative CS differences (not shown), which is opposite to the result in Figure 5c. Nevertheless, not every crop/NETT combination area shows significant decreases in $\mathrm{CS}$, including the southern parts and the northeastern parts of SC, which implies the significance of other factors that are responsible for the differences in CS other than the dominant vegetation types (e.g., soil type, topography, landatmosphere interactions, and transport of air and moisture).

[16] The substantial reductions in CS by the inclusion of vegetation, such as in $\mathrm{NE}, \mathrm{UC}$, and $\mathrm{SC}$, indicates that the vegetation contributes to desertification mitigation. This phenomenon is due to the fact that the changes in CS 
(a) $\Delta(P-E)$

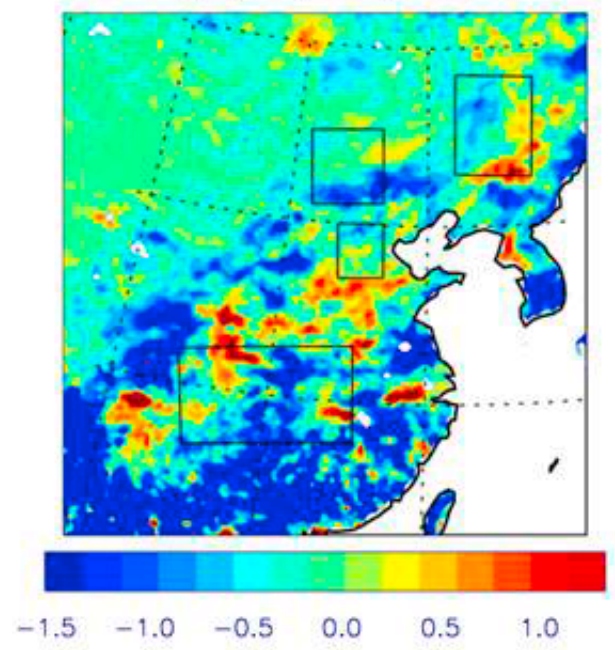

(b) $\Delta \mathrm{SM}$

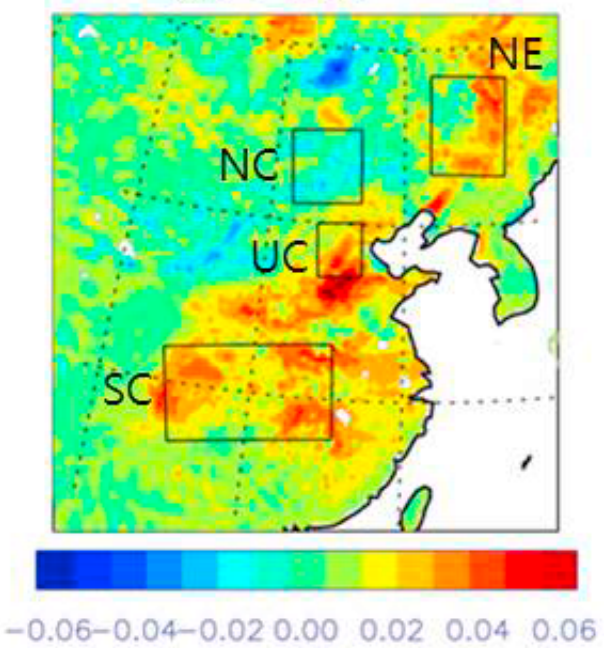

Figure 3. Differences (VEG-NOVEG) of (a) precipitation minus evapotranspiration, $\bar{P}-\bar{E}$, and (b) soil moisture in the top $1.8 \mathrm{~cm}$ layer, $\overline{S M}$, in JJA. Units in Figure $3 \mathrm{a}$ are $\mathrm{mm} / \mathrm{d}$.

significantly affect regional hydrological characteristics and aridity. Studies on warm season droughts over the transition zones in the midlatitude suggest that, although long-lasting serious droughts are initiated by abnormal large-scale circulations, the significant roles of the land surface interactions with the atmosphere cannot be neglected since they maintain and amplify the initial droughts, which leads to long-lasting droughts [Schubert et al., 2004]. Considering this mechanism of droughts, the presence of a CS reduction theoretically implies that those regions can be affected not only by less intense but also by less frequent summer droughts due to vegetation since the positive feedback between the atmosphere and the land surface is less likely to amplify an original precipitation deficit.

[17] This speculation is consistent with the changes of JJA mean soil moisture, $\overline{S M}$ (Figure $3 \mathrm{~b}$ ). Moisture in the soil of the top layer is highly variable and directly influences surface evapotranspiration and energy flux. It is a reliable proxy for drought indices such as the Palmer Drought Severity Index (PDSI) over snow-free regions [Dai et al., 2004] in that it reflects the aggregate effect of the hydrologic processes in the soil, vegetation, and atmosphere as well as their interactions at various time scales. Table 2 shows that lower CS is coincident with wetter soil in NE, UC, and SC, and vice versa in NC. The difference of $\overline{S M}$ between VEG and NOVEG was statistically significant at the $95 \%$ level in the four sub study regions. The wetter soil in the VEG over NE, UC, and SC might result from increased JJA mean of precipitation minus evapotranspiration $(\bar{P}-\bar{E})$ as well, as discussed previously in the section 3.1. However, the difference in $\bar{P}-\bar{E}$ was negative (Table 2), and the impact of vegetation on $\bar{P}-\bar{E}$ was inconsistent with that on $\overline{S M}$ over those study regions. The difference between $\overline{S M}$ and $\bar{P}-\bar{E}$ was not fully explained by changes in runoff (not shown). These results are interesting because the difference (VEG minus NOVEG) of mean soil moisture appears to be linked with those of CS that is based on the anomalies of $P$ and $E$. Thus, the opposite tendency of the differences in CS and soil moisture shown in Table 2 alludes that CS reduction decreases local vulnerability to drought by changing the land-atmosphere feedback characteristics and local climate, which ultimately tends to alleviate desertification in East Asia.

\subsection{Identification of the Most Effective Regions of Tree Planting}

[18] While vegetation tends to modulate local coupling strength significantly, the impact of vegetation on the CS as shown in Figure 5c may be subject to vegetation fraction since the VEG experiment implemented the vegetation close to current status in CLM. In an attempt to remove this dependency, the difference of CS (VEG minus NOVEG) divided by the JJA mean vegetation fraction (shown in Figure 1) is calculated and shown in Figure 5d (normalized difference of CS; NDCS). Comparison of Figure 5c with Figure $5 \mathrm{~d}$ demonstrates that while NDCS is slightly reduced over the densely distributed vegetation regions such as the northeastern and southwestern domains, a strong reduction of NDCS is still predominant over the regions where the difference in the nonnormalized CS (Figure 5d) is large. In particular, NDCS is significantly noticeable over the areas with vegetation fractions $<50 \%$ (indicated by black contours in Figure 5d). These areas include the eastern peripheries of Gobi desert, Manchurian Plains (NE), and fast urbanization areas in central China (UC). In particular, NE and UC are acknowledged as being the most hazardous regions in which the fast transition from greenness to aridness has occurred over the past several decades [Xuejie et al., 2003]. Figure $5 \mathrm{~d}$ suggests that tree planting over these regions would reduce $\mathrm{CS}$ more considerably than would planting over the other regions and mitigate desertification of East Asia in terms of atmosphere-land coupling.

[19] For the identification and suggestion of the most effective regions for tree planting in Figure $5 \mathrm{~d}$ to be valid, the impact of afforestation on CS should be a locally oriented process (i.e., changes in evapotranspiration) rather than a remotely oriented process (i.e., large-scale circulation and 
(a) VEG experiment
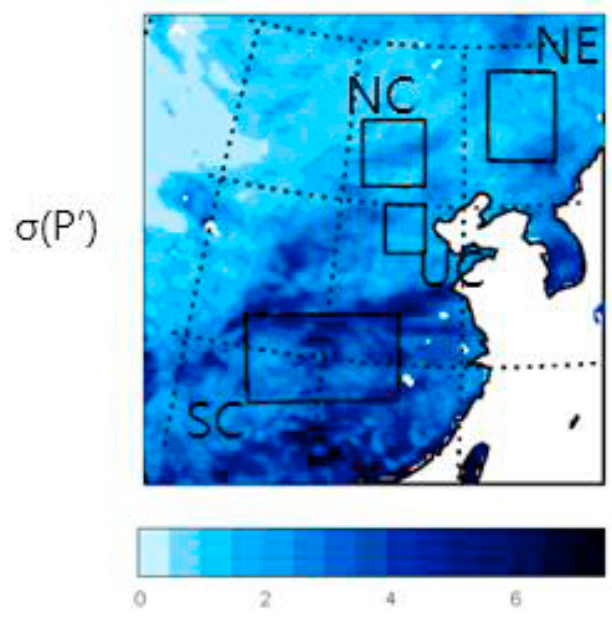

(c) VEG experiment

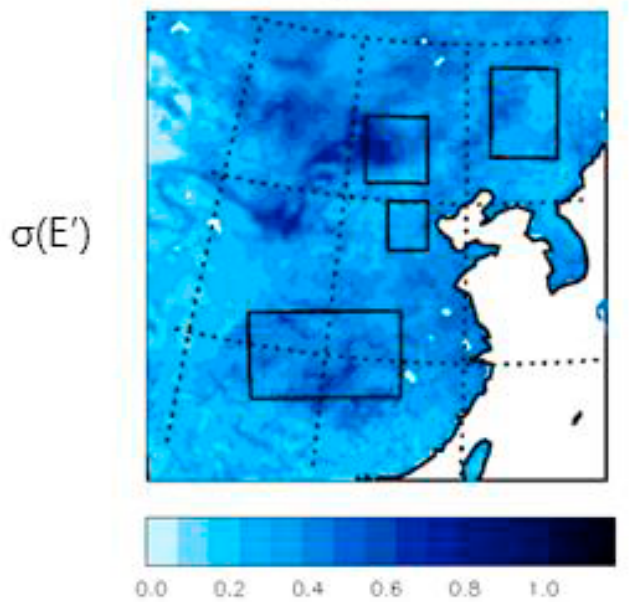

(b) VEG minus NOVEG (significant area only)
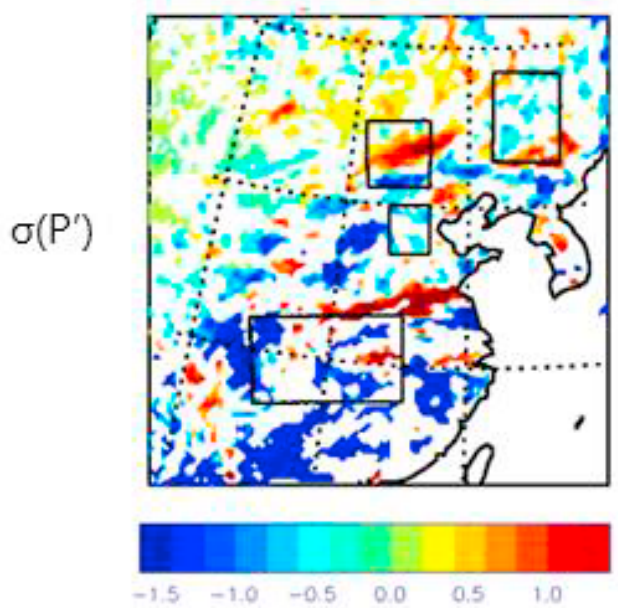

(d) VEG minus NOVEG (significant area only)

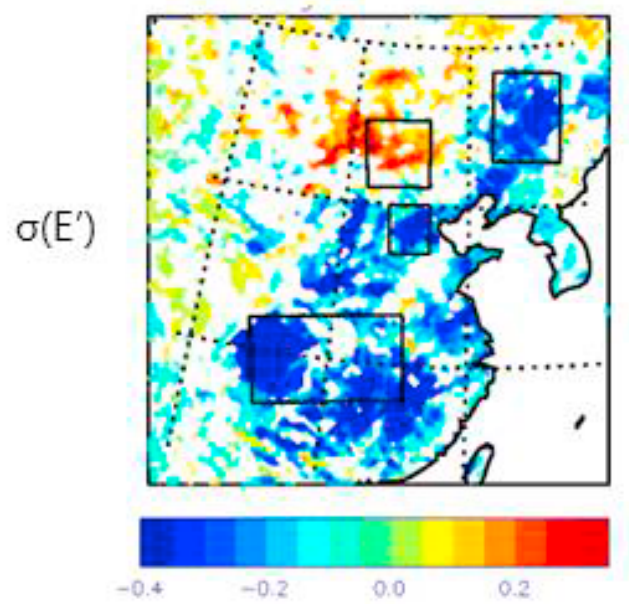

Figure 4. (a) Standard deviation of monthly anomalies of precipitation in VEG and (b) its difference between VEG and NOVEG in JJA (areas significantly different at a 95\% confidence level). (c and d) The same as in Figures $4 a$ and $4 b$ but for monthly anomalies of evapotranspiration. Units are $\mathrm{mm} / \mathrm{d}$.

associated moisture flux divergence). One way to test this hypothesis is to determine whether moisture transports from other regions play an important role in precipitation variability. If vegetation-induced CS changes are mainly associated with great changes in moisture flux divergence ( $M F D$, hereafter) instead of evapotranspiration, the influence of afforestation on CS occurs remotely and then the local modulation of CS in one area becomes sensitive to the specific locations of the trees planted elsewhere. In this case, finding the most effective tree planting areas requires a complicated set of model experiments, and the result is less reliable.

[20] Neglecting surface runoff and drainage, $P, E$, and $M F D$ are interrelated according to the approximation of the surface hydrologic balances on a monthly time scale $(M F D=P-E)$ and; thus, monthly anomalous $M F D\left(M F D^{\prime}\right)$ was estimated from the monthly precipitation and evapotranspiration. Figure 6 displays the differences in the area-averaged standard deviations of $M F D^{\prime}$ between VEG and NOVEG $\left[\triangle \sigma\left(M F D^{\prime}\right)\right]$ in each selected region. Similarly, $\left[\Delta \sigma\left(P^{\prime}\right)\right]$ and $\left[\Delta \sigma\left(E^{\prime}\right)\right]$ for the anomalies of $P$ and $E$, respectively. Although $\left[\Delta \sigma\left(M F D^{\prime}\right)\right]$ is commensurate with that of $\left[\Delta \sigma\left(E^{\prime}\right)\right]$ in magnitude over NC, Figure 6 indicates not only that the absolute magnitudes of $\left[\Delta \sigma\left(M F D^{\prime}\right)\right]$ are much less than those of $\left[\Delta \sigma\left(E^{\prime}\right)\right]$ but also that $\left[\Delta \sigma\left(P^{\prime}\right)\right]$ are mainly related with $\left[\Delta \sigma\left(E^{\prime}\right)\right]$ in sign over NE, $\mathrm{UC}$, and SC. The former result implies the smaller magnitudes of $M F D^{\prime}$ compared to $P^{\prime}$ and $E^{\prime}$, because $P^{\prime}, E^{\prime}$, and $M F D^{\prime}$ are quantities of anomalies and their standard deviations are likely to be proportional to their absolute magnitudes. When the surface runoff and drainage are also taken into account, the $M F D^{\prime}$ magnitudes are expected to be even smaller than those shown in Figure 6. Although this analysis does not completely eliminate the possibility of remote impact of afforestation on $\mathrm{CS}$ in other regions, the result in Figure 6 is indicative of the fact that vegetation controls the CS rather locally. In this respect, Figure $5 \mathrm{~d}$ provides valuable information about the most effective regions of tree planting for desertification mitigation in terms of atmosphere-land CS. 
(a) Coupling strength, VEG



(c) VEG-NOVEG Difference

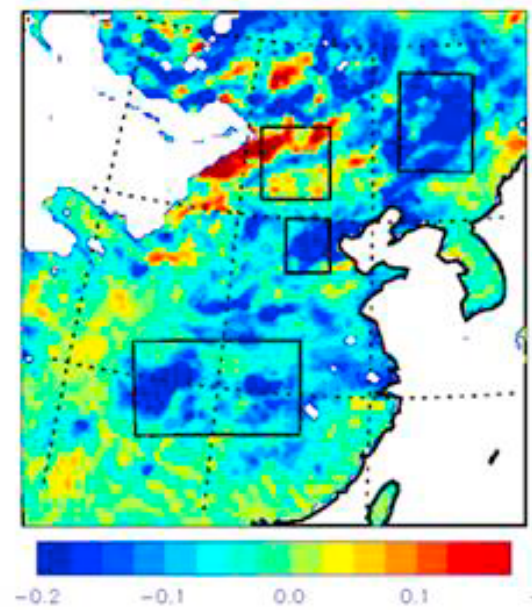

(b) Coupling strength, NOVEG

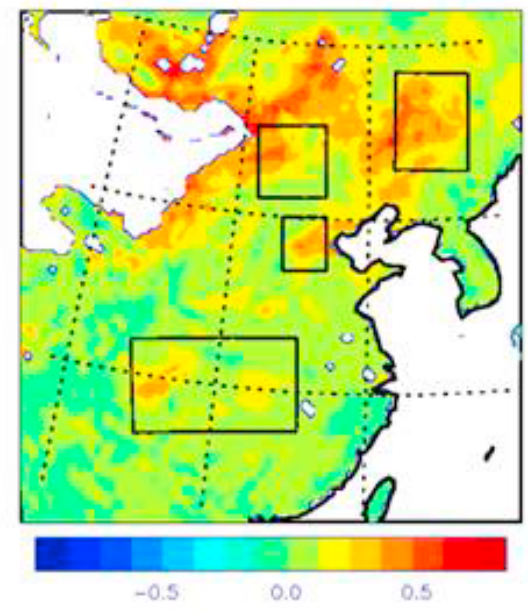

(d) Normalized difference by vegetation fraction

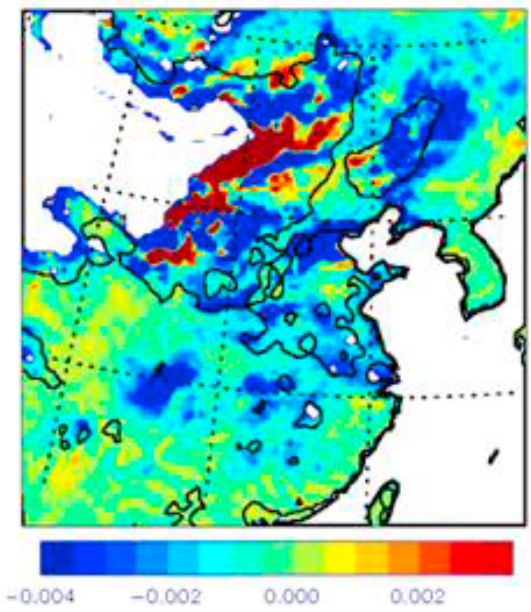

Figure 5. Coupling strength in (a) VEG and (b) NOVEG, (c) difference of the coupling strength (VEGNOVEG), and (d) the normalized difference of the coupling strength (NDCS) in JJA. Black contours in Figure $5 \mathrm{~d}$ represent $50 \%$ of the vegetation fraction.

\subsection{Causes on the Changes in Coupling Strength}

[21] According to equation (1), it is reasonable to assume that the differences of CS may be associated with changes of signs in $P_{i}^{\prime} \cdot E_{i}^{\prime}$ and/or absolute magnitude of $\mathrm{CS}\left(=\frac{\sum_{i=1}^{N}\left|P_{i}^{\prime} \cdot E_{i}^{\prime}\right|}{\sum_{i=1}^{N} P_{i}^{\prime 2}}\right)$. For the numerator $\left(\sum_{i=1}^{N} P_{i}^{\prime} \cdot E_{i}^{\prime}\right)$, changes can be induced by either or both of the following: (1) changes in number of cases with opposite signs between $P^{\prime}$ and $E^{\prime}$, thus with a negative sign of $P_{i}^{\prime} \cdot E_{i}^{\prime}$ (decoupling frequency, hereafter), and (2) changes in the sign-neglected magnitude of $P_{i}^{\prime} \cdot E_{i}^{\prime}\left(=\left|P_{i}^{\prime} \cdot E_{i}^{\prime}\right|\right)$. Change of decoupling frequency is higher in UC and SC (14.8\% and $14.6 \%$, respectively) than in $\mathrm{NC}$ and $\mathrm{NE}(-3.1 \%$, and $8.7 \%$, respectively), but

Table 2. Area-Averaged Difference (VEG-NOVEG) in CS ( $\triangle \mathrm{CS})$ with a p Value, Mean Soil Moisture of the Top $1.8 \mathrm{~cm}$ Layer $(\overline{S M})$ With a $\mathrm{p}$ Value, Mean Precipitation Minus Evapotranspiration $(\bar{P}-\bar{E})$, and NDCS in NC, NE, UC and SC during JJA ${ }^{\text {a }}$

\begin{tabular}{lcccc}
\hline Region & $\Delta \mathrm{CS}$ & $\Delta \overline{S M}$ & $\Delta(\bar{P}-\bar{E})$ & $\Delta \mathrm{NDCS}$ \\
\hline NC & $0.035(18.32 \%)$ and 0.1619 & $-0.011(-5.1 \%)$ and 0.009 & -0.407 & 0.0041 \\
NE & $-0.13(-43.6 \%)$ and 0.0305 & $0.010(4.8 \%)$ and 0.009 & -0.159 & -0.0026 \\
UC & $-0.134(-79.3 \%)$ and 0.0113 & $0.025(10.9 \%)$ and 0.029 & -0.148 & -0.0029 \\
SC & $-0.081(-83.5 \%)$ and 0.0157 & $0.020(6.8 \%)$ and 0.023 & -0.424 & -0.0014 \\
\hline
\end{tabular}

${ }^{\mathrm{a}}$ Italicized numbers indicate $\mathrm{p}$ values. Differences in percentage per the value of the NOVEG experiment are shown in parenthesis. The unit of $\bar{P}-\bar{E}$ is $\mathrm{mm} / \mathrm{d}$. 


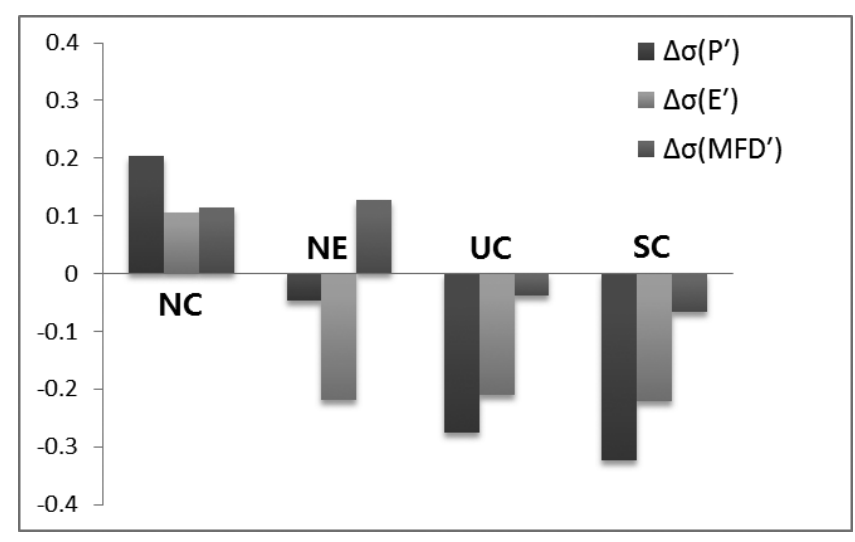

Figure 6. Differences of area-averaged standard deviations of the anomalies of precipitation, evapotranspiration, and moisture flux divergence between VEG and NOVEG $\left(\left[\Delta \sigma\left(P^{\prime}\right)\right],\left[\Delta \sigma\left(E^{\prime}\right)\right]\right.$, and $\left[\Delta \sigma\left(M F D^{\prime}\right)\right]$, respectively) in $\mathrm{NC}$, $\mathrm{NE}, \mathrm{UC}$, and SC. A unit is $\mathrm{mm} / \mathrm{d}$.

it is less than $15 \%$. On the other hand, the original CS $\left(=\frac{\sum_{i=1}^{N} P_{i}^{\prime} \cdot E_{i}^{\prime}}{\sum_{i=1}^{N} P_{i}^{2}}\right)$ and the sign-neglected CS $\left(=\frac{\sum_{i=1}^{N}\left|P_{i}^{\prime} \cdot E_{i}^{\prime}\right|}{\sum_{i=1}^{N} P_{i}^{2}}\right)$ averaged over the selected regions for the VEG and NOVEG experiments are shown in Table 3. Differences in the original CS are the same values as shown in Table 2. For either VEG or NOVEG, the sign-neglected CS was higher than the original CS, especially in UC and SC, but the VEG-NOVEG differences did not change much between the original case and the sign-neglected case; in fact, they remained almost the same in NE and NC and slightly increased in UC and SC. This result implies that the changes in the absolute magnitude of $\operatorname{CS}\left(\frac{\sum_{i=1}^{N}\left|P_{i}^{\prime} \cdot E_{i}^{\prime}\right|}{\sum_{i=1}^{N} P_{i}^{\prime 2}}\right)$ is more critical to the induction of significant CS changes between VEG and NOVEG than the changes in decoupling frequency.

[22] Changes in CS may be more sensitive to changes in the value of the denominator than those in the numerator. Table 4 displays area-averaged amounts of numerators (signneglected value, $\left.\sum_{i=1}^{N}\left|P_{i}^{\prime} \cdot E_{i}^{\prime}\right|\right)$ and denominators $\left(\sum_{i=1}^{N} P_{i}^{\prime 2}\right)$ and their differences (\%) between VEG and NOVEG. In all of the selected regions, numerator changes were much greater than denominator changes, which consequently determine the signs of the CS differences.

[23] Furthermore, changes in the absolute magnitude of $\mathrm{CS}$ are attributed to larger changes in $E^{\prime}$ than in $P^{\prime}$. This feature is supported by Figure 7, which shows the differences (in percent) of the area-averaged standard deviations

Table 3. Area-Averaged Original and Sign-Neglected CS of VEG and NOVEG and Their Differences

\begin{tabular}{lccccccc}
\hline & \multicolumn{3}{c}{ Original CS } & & \multicolumn{3}{c}{ Sign-Neglected CS } \\
\cline { 2 - 4 } \cline { 6 - 7 } & VEG & NOVEG & Diff & & VEG & NOVEG & Diff \\
\hline NC & 0.226 & 0.191 & 0.035 & & 0.227 & 0.191 & 0.036 \\
NE & 0.168 & 0.298 & -0.13 & & 0.171 & 0.299 & -0.128 \\
UC & 0.035 & 0.169 & -0.134 & & 0.047 & 0.171 & -0.124 \\
SC & 0.016 & 0.097 & -0.081 & & 0.031 & 0.102 & -0.071 \\
\hline
\end{tabular}

Table 4. Area-Averaged Sign-Neglected Numerator and Denominator in Equation (1) of VEG and NOVEG and the Differences

\begin{tabular}{cccccccc}
\hline & \multicolumn{3}{c}{$\begin{array}{c}\text { Sign-Neglected Numerator } \\
\left(\sum_{i=1}^{N} \mid P_{i}^{\prime} \cdot E_{i}^{\prime}\right)\end{array}$} & & \multicolumn{3}{c}{$\begin{array}{c}\text { Denominator } \\
\left(\sum_{i=1}^{N} P_{i}^{\prime 2}\right)\end{array}$} \\
\cline { 8 - 9 } \cline { 7 - 8 } & VEG & NOVEG & $\begin{array}{c}\text { Difference } \\
(\%)\end{array}$ & & VEG & NOVEG & $\begin{array}{c}\text { Difference } \\
(\%)\end{array}$ \\
\hline NC & 24.35 & 13.14 & 85.3 & & 128.38 & 93.46 & 38.3 \\
NE & 14.30 & 30.19 & -52.6 & & 108.10 & 106.79 & 1.2 \\
UC & 6.26 & 30.96 & -80.0 & & 162.56 & 217.12 & -25.1 \\
SC & 17.39 & 64.80 & -73.2 & & 645.18 & 782.29 & -17.5 \\
\hline
\end{tabular}

of $P^{\prime}$ and $E^{\prime}$ between VEG and NOVEG $\left(\Delta P^{\prime}\right.$ and $\left.\Delta E^{\prime}\right)$ in each selected region. Here, $\Delta P^{\prime}$ and $\Delta E^{\prime}$ were computed as:

$$
\Delta P^{\prime}\left(\text { or } \Delta E^{\prime}\right)=\frac{\sigma_{\mathrm{VEG}}\left(P^{\prime} \text { or } E^{\prime}\right)-\sigma_{\mathrm{NOVEG}}\left(P^{\prime} \text { or } E^{\prime}\right)}{\sigma_{\mathrm{NOVEG}}\left(P^{\prime} \text { or } E^{\prime}\right)} \times 100 .
$$

[24] Note that first, $\Delta P^{\prime}$ and $\Delta E^{\prime}$ are close estimates of the difference of absolute magnitudes of $P^{\prime}$ and $E^{\prime}$ between VEG and NOVEG. Second, the magnitude of $P^{\prime}$ tends to be inversely proportional to CS due to the cancellation effect of $P^{\prime}$ in the numerator by $P^{\prime 2}$ in the denominator in equation (1), but the magnitude of $E^{\prime}$ is proportional to CS. According to Figure 7, in NC, where $\triangle \mathrm{CS}$ is positive in Figures $5 \mathrm{c}$ and $5 \mathrm{~d}$, the positive changes of CS stems from the larger increase in $E^{\prime}$, while the increase in $P^{\prime}$ tends to decrease CS. Similarly, in the other three regions (NE, UC, and SC), where $\triangle \mathrm{CS}$ is negative, the reduction of CS is mainly caused by larger decreases in $E^{\prime}$ despite the decrease in $P^{\prime}$.

[25] This analytical result is indicative of the significant modulation of vegetation on CS, primarily through modifying the evapotranspiration variability. This is confirmed by the variability changes of evapotranspiration in Figure $4 d$ corresponding with the changes of CS in Figure 5c over most of the domain. Evapotranspiration in CLM is a complex function of several variables, such as surface wind speed, temperature, humidity, and aerodynamic leaf and surface resistance. Furthermore, on a daily or monthly time scale,

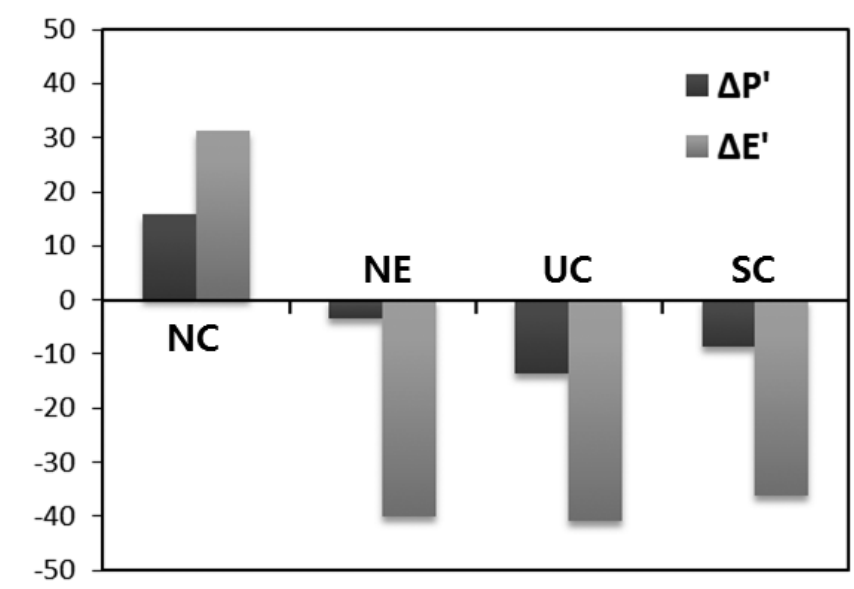

Figure 7. Differences in percentage of area-averaged standard deviations of the anomalies of precipitation and evapotranspiration between VEG and NOVEG $\left(\Delta P^{\prime}\right.$ and $\left.\Delta E^{\prime}\right)$ in $\mathrm{NC}, \mathrm{NE}, \mathrm{UC}$, and $\mathrm{SC}$. 
complicated interactions arise between land surface variables in CLM and atmospheric variables in WRF by coupling the models with the land surface and by boundary layer processes as described in the section 2 . This is why CS responds differently over the same PFT regions as discussed in Figure 5. Declines of the standard deviation of evapotranspiration anomalies signify that the vegetation helps keep the evapotranspiration constant. The soil moisture memory in the dry areas appears to be short because its water-holding capacity is low due to its sparse vegetation; as such, it is probable that planting trees over these regions would affect evapotranspiration, runoff, and, ultimately, soil moisture [Koster and Suarez, 2001; Wu and Dickinson, 2004]. Indeed, supporting this speculation, the longer memory of the top $1.8 \mathrm{~cm}$ soil layer in the VEG compared to the NOVEG experiment was discovered over dry regions of East Asia in this study (not shown). As a result, combination of the results in Figures 5 and 7 suggests that vegetation is likely to alter local evapotranspiration and precipitation variability and then change the atmosphere-land CS in the dry lands of East Asia.

\section{Discussion and Conclusions}

[26] This study investigated the impact of vegetation on the hydrological coupling between land and atmosphere, based on the simulations of the WRF-CLM coupled model. We found that vegetation is predisposed to reduce the atmosphere-land linkage and to increase soil moisture over the several dry and wet regions in East Asia. This potential impact of vegetation is worth taking into account, because various attempts to mitigate desertification have been made, with the fundamental concepts of drought and desertification (i.e., maintenance of droughts by strong feedbacks between the atmosphere and land) missing. This study reports for the first time, to our knowledge, the indirect but fundamental impact of vegetation on the CS between the atmosphere and the land surface.

[27] The most important hydrological factor in the CS change by vegetation appears to be evapotranspiration: vegetation tends to reduce the variability of evapotranspiration like a water reservoir in the soil and then diminish the CS. The vegetation-induced CS declines result in enhanced JJA mean soil moisture (Table 2), suggesting decreases in drought intensity and/or occurrence. However, this effect is limited in some regions such as the northern central domain (NC). Although our VEG and NOVEG experiments are not ideal for directly describing afforestation effects, this result suggests that an afforestation effect may have a unique contribution to desertification mitigation. After testing the regional dependency of the impact of vegetation on CS, this study ultimately suggests several key regions including the Manchurian Plains (NE) and the rapid urbanization areas in central China (UC) as the most efficient areas for vegetation planting with respect to CS reduction. Identification of the most influential areas of afforestation with respect to the modification of the land-atmosphere CS and the tree planting over those areas is referred to as the acupuncture-like afforestation.

[28] While previous studies regarding deforestation and afforestation have focused on the impacts of vegetation on changes in the mean characteristics of surface temperature, precipitation, surface energy fluxes or large- and local-scale circulations, this study emphasizes the significance of the hydrological coupling strength that takes into account only the anomalies of precipitation and evapotranspiration. One may expect that the increase in $\bar{P}$ or $\bar{P}-\bar{E}$ would be more important to mitigate desertification. However, with respect to hydrological extreme events such as floods and droughts, the climate variability rather than its average has been considered to be more important [Katz and Brown, 1992; Schär et al., 2004]. Furthermore, changes in the climate variability (e.g., coupling strength) would induce a substantial change in the averages in a longer time scale, ultimately. We found that JJA mean soil moisture can increase, despite decreased $\bar{P}-\bar{E}$ in many East Asian regions where the reduction of CS by vegetation was pronounced (Table 2). Namely, the mean precipitation is not always directly associated with the probability of drought over dry lands. We, therefore, demonstrated that changes in CS rather than those in the mean precipitation by tree planting are more decisive for desertification mitigation.

[29] This study revisited the conventional tree planting approach as an essential and effective strategy for desertification mitigation with respect to the hydrological coupling strength. One of the drawbacks of this study is lack of complete mechanical explanations about the connections between $\mathrm{CS}$ and soil moisture. It is necessary to further investigate detailed processes of the modulation of soil moisture by CS. Specifically, further studies require careful and profound analyses considering complete hydrological cycles among the atmosphere, soil, and vegetation with respect to both mean and anomaly fields of hydrological variables, based on much longer simulations than 5 years. This remains to be investigated as the future study. Another drawback of this study is related with a dependency of vegetation species on CS. Based on the effect of the currently dominant vegetation types on the CS, this study focused on the question of where to plant to combat desertification. The question of which species strengthen or weaken CS in terms of desertification mitigation remains significant, although it is suggested that crop (grass) is likely to weaken (intensify) CS (Figures 1 and 5) in this study. Unfortunately, adaptation of the multiple PFTs at a grid in CLM prevents further analyses from finding the answers to the latter question. In addition, assuming prescribed vegetation, interactions and feedback between vegetation and climate are not considered in this study. Therefore, future studies should enlighten the dependency of vegetation species and the impact of interactions between vegetation and climate on CS.

[30] This study dealt with the climatic impact of vegetation in the present climate only. However, many future projections of the double $\mathrm{CO}_{2}$ environments using general circulation models (GCMs) show that the short-term and long-term drought frequencies would increase greatly over the globe since they are associated with changes in Hadley circulations and northward replacement of major storm tracks in the northern hemisphere [Giorgi, 2006; Sheffield and Wood, 2008]. Especially over the Mediterranean and southern Europe, one of the high-risk frequent drought regions, enhanced precipitation-temperature-soil moisture coupling in the double $\mathrm{CO}_{2}$ climate has been simulated [Seneviratne et al., 2006; Giorgi and Lionello, 2008]. In this circumstance, the acupuncture-like afforestation is expected 
to lessen the potential impacts of global warming on drought probability and desert expansion.

[31] This study examined only the vegetation-induced hydrological coupling between the atmosphere and land surface, especially during the summer, although desertification can also be locally affected by nonmeteorological factors e.g., chemical and biological deterioration of the soil [Conant et al., 2001; Su et al., 2004; Steffens et al., 2008] and changes in land use due to grazing, cultivation, and fire [Evans and Geerken, 2004] induced by human interferences. However, these nonmeteorological factors may eventually alter CS through various effects as well and can affect desertification. Consequently, one has to be attentive to CS modulation and its influences on desertification mitigation.

[32] Acknowledgments. This work was supported by the Basic Science Research Program through the National Foundation of Korea (NRF), funded by the Ministry of Education, Science and Technology (2012-0000857), and the Korea Meteorological Administration Research and Development Program under grant CATER 2012-3064. We thank anonymous reviewers for their insightful comments on an earlier draft of this article.

\section{References}

Bonan, G. B., D. Pollard, and S. L. Thompson (1992), Effects of boreal forest vegetation on global climate, Nature, 359, 716-718, doi:10.1038/ $359716 \mathrm{a} 0$.

Conant, R. T., K. Paustian, and E. T. Elliott (2001), Grassland management and conversion into grassland: Effects on soil carbon, Ecol. Appl., 11, 343-355, doi:10.1890/1051-0761(2001)011[0343:GMACIG]2.0.CO;2.

Dai, A., K. E. Trenberth, and T. Qian (2004), A global data set of Palmer Drought Severity Index for 1870-2002: Relationship with soil moisture and effects of surface warming, J. Hydrometeorol., 5, 1117-1130, doi:10.1175/JHM-386.1.

Evans, J., and R. Geerken (2004), Discrimination between climate and human-induced dryland degradation, J. Arid Environ., 57, 535-554, doi:10.1016/S0140-1963(03)00121-6.

Farley, K. A., E. G. Jobbágy, and R. B. Jackson (2005), Effects of afforestation on water yield: A global synthesis with implications for policy, Global Change Biol., 11, 1565-1576, doi:10.1111/j.1365-2486.2005.01011.x.

Foley, J. A. (1994), Net primary productivity in the terrestrial biosphere: The application of a global model, J. Geophys. Res., 99, 20,773-20,783, doi:10.1029/94JD01832.

Giorgi, F. (2006), Climate change hot-spots, Geophys. Res. Lett., 33, L08707, doi:10.1029/2006GL025734.

Giorgi, F., and P. Lionello (2008), Climate change projections for the Mediterranean region, Global Planet. Change, 63, 90-104, doi:10.1016/ j.gloplacha.2007.09.005.

Henderson-Sellers, A., R. E. Dickinson, T. B. Durbidge, P. J. Kennedy, K. Mcguffie, and A. J. Pitman (1993), Tropical deforestation: Modeling local- to regional-scale climate change, J. Geophys. Res., 98, 7289-7315, doi:10.1029/92JD02830.

Hong, S. Y., and E. Kalnay (2002), The 1998 Oklahoma-Texas drought: Mechanistic experiments with NCEP global and regional models, J. Clim., 15, 945-963, doi:10.1175/1520-0442(2002)015<0945:TOTDME>2.0.CO;2.

Husar, R. B., et al. (2001), Asian dust events of April 1998, J. Geophys. Res., 106, 18,317-18,330, doi:10.1029/2000JD900788.

Jackson, R. B., et al. (2000), Belowground consequences of vegetation change and their treatment in models, Ecol. Appl., 10, 470-483, doi:10.1890/1051-0761(2000)010[0470:BCOVCA]2.0.CO;2.

Jeong, S.-J., C.-H. Ho, K.-Y. Kim, and J.-H. Jeong (2009), Reduction of spring warming over East Asia associated with vegetation feedback, Geophys. Res. Lett., 36, L18705, doi:10.1029/2009GL039114.

Jeong, S.-J., C.-H. Ho, T.-W. Park, J. Kim, and S. Levis (2011a), Impact of vegetation feedback on the temperature and its diurnal range over the Northern Hemisphere during summer in a $2 \times \mathrm{CO}_{2}$ climate, Clim. Dyn., 37, 821-833, doi:10.1007/s00382-010-0827-x.

Jeong, S.-J., C.-H. Ho, M. Brown, J.-S. Kug, and S. Piao (2011b), Browning in desert boundaries over Asia in the recent decades, J. Geophys. Res., 116, D02103, doi:10.1029/2010JD014633.

Katz, R. W., and B. G. Brown (1992), Extreme events in a changing climate: Variability is more important than averages, Clim. Change, 21, 289-302, doi:10.1007/BF00139728.
Koster, R. D., and M. J. Suarez (2001), Soil moisture memory in climate models, J. Hydrometeorol., 2, 558-570, doi:10.1175/1525-7541(2001) $002<0558$ :SMMICM>2.0.CO;2.

Koster, R. D., et al. (2004), Regions of strong coupling between soil moisture and precipitation, Science, 305, 1138-1140, doi:10.1126/ science. 1100217 .

Koster, R. D., et al. (2006), GLACE: The Global Land-Atmosphere Coupling Experiment. Part I: Overview, J. Hydrometeorol., 7, 590-610, doi:10.1175/JHM510.1.

Lin, M.-L., et al. (2009), Fuzzy model-based assessment and monitoring of desertification using MODIS satellite imagery, Eng. Comput., 26, 745-760, doi:10.1108/02644400910985152.

Namias, J. (1982), Anatomy of Great Plains protracted heat waves (especially the 1980 U.S. summer drought), Mon. Weather Rev., 110, 824-838, doi:10.1175/1520-0493(1982)110<0824:AOGPPH>2.0.CO;2.

Oleson, K. W., et al. (2004), Technical description of the Community Land Model (CLM), NCAR Tech. Note NCAR/TN-461+STR, National Center for Atmospheric Research, Boulder, Colo.

Pielke, R. A., Sr., R. Avissar, M. Raupach, A. J. Dolman, X. Zeng, and A. S. Denning (1998), Interactions between the atmosphere and terrestrial ecosystems: Influence on weather and climate, Global Change Biol., 4 461-475, doi:10.1046/j.1365-2486.1998.t01-1-00176.x.

Pielke, R. A., Sr., J. Adegoke, A. Beltrán-Przekurat, C. A. Hiemstra, J. Lin, U. S. Nair, D. Niyogi, and T. E. Nobis (2007), An overview of regional land use and land cover impacts on rainfall, Tellus, Ser. B, 59, 587-601, doi:10.1111/j.1600-0889.2007.00251.x.

Prentice, C., M. Heimann, and S. Sitch (2000), The carbon balance of the terrestrial biosphere: Ecosystem models and atmospheric observations, Ecol. Appl., 10, 1553-1573, doi:10.1890/1051-0761(2000)010[1553: TCBOTT]2.0.CO;2.

Rotenberg, E., and D. Yakir (2010), Contribution of semi-arid forests to the climate system, Science, 327, 451-454, doi:10.1126/science.1179998.

Sahin, V., and M. J. Hall (1996), The effects of afforestation and deforestation on water yields, J. Hydrol., 178, 293-309, doi:10.1016/ 0022-1694(95)02825-0.

Schär, C., P. L. Vidale, D. Lüthi, C. Frei, C. Häberli, M. A. Liniger, and C. Appenzeller (2004), The role of increasing temperature variability in European summer heatwaves, Nature, 427, 332-336, doi:10.1038/ nature 02300 .

Schubert, S. D., M. J. Suarez, P. J. Pegion, R. D. Koster, and J. T. Bacmeister (2004), Causes of long-term drought in the U.S. Great Plains, J. Clim., 17, 485-503, doi:10.1175/1520-0442(2004)017<0485:COLDIT>2.0.CO;2.

Sen, O. L., Y. Wang, and B. Wang (2004), Impact of Indochina deforestation on the East Asian summer monsoon, J. Clim., 17, 1366-1380, doi:10.1175/1520-0442(2004)017<1366:IOIDOT>2.0.CO;2.

Seneviratne, S. I., D. Lüthi, M. Litschi, and C. Schär (2006), Landatmosphere coupling and climate change in Europe, Nature, 443, 205-209, doi:10.1038/nature05095.

Sheffield, J., and E. F. Wood (2008), Projected changes in drought occurrence under future global warming from multi-model, multi-scenario, IPCC AR4 simulations, Clim. Dyn., 31, 79-105, doi:10.1007/s00382007-0340-Z

Steffens, M., A. Kölbl, K. U. Totsche, and I. Kögel-Knabner (2008), Grazing effects on soil chemical and physical properties in a semiarid steppe of Inner Mongolia (P.R. China), Geoderma, 143, 63-72, doi:10.1016/j. geoderma.2007.09.004.

Su, Y.-Z., H.-L. Zhao, T.-H. Zhang, and X.-Y. Zhao (2004), Soil properties following cultivation and non-grazing of a semi-arid sandy grassland in northern China, Soil Tillage Res., 75, 27-36, doi:10.1016/S0167-1987 (03)00157-0.

Sud, Y. C., D. M. Mocko, K. M. Lau, and R. Atlas (2003), Simulating the midwestern U.S. drought of 1988 with a GCM, J. Clim., 16, 3946-3965, doi:10.1175/1520-0442(2003)016<3946:STMUDO>2.0.CO;2.

Swann, A. L. S., I. Y. Fung, and J. C. H. Chiang (2012), Mid-latitude afforestation shifts general circulation and tropical precipitation, Proc. Natl. Acad. Sci. U. S. A., 109, 712-716, doi:10.1073/pnas.1116706108.

Trenberth, K. E., G. W. Branstator, and P. A. Arkin (1988), Origins of the 1988 North American drought, Science, 242, 1640-1645, doi:10.1126/ science.242.4886.1640.

United Nations Convention to Combat Desertification (UNCCD) (2004), Preserving our common ground: UNCCD 10 years on, anniversary report, Bonn, Germany.

Wang, G., Y. Kim, and D. Wang (2007), Quantifying the strength of soil moisture-precipitation coupling and its sensitivity to changes in surface water budget, J. Hydrometeorol., 8, 551-570, doi:10.1175/JHM573.1.

Wu, W., and R. E. Dickinson (2004), Time scales of layered soil moisture memory in the context of land-atmosphere interaction, J. Clim., 17, 2752-2764, doi:10.1175/1520-0442(2004)017<2752:TSOLSM>2.0.CO;2. 
Xue, Y. K. (1996), The impact of desertification in the Mongolian and in the inner Mongolian grassland on the regional climate, J. Clim., 9, 2173-2189, doi:10.1175/1520-0442(1996)009<2173:TIODIT >2.0.CO;2.

Xue, Y., and J. Shukla (1993), The influence of land surface properties on Sahel climate. Part 1: Desertification, J. Clim., 6, 2232-2245, doi:10.1175/1520-0442(1993)006<2232:TIOLSP >2.0.CO;2.

Xue, Y., H.-M. H. Juang, W.-P. Li, S. Prince, R. DeFries, Y. Jiao, and R. Vasic (2004), Role of land surface processes in monsoon development: East Asia and West Africa, J. Geophys. Res., 109, D03105, doi:10.1029/ 2003JD003556.

Xuejie, G., L. Yong, L. Wantao, Z. Zongci, and F. Giogi (2003), Simulation of effects of land use change on climate in China by a regional climate model, Adv. Atmos. Sci., 20, 583-592, doi:10.1007/BF02915501.
Yang, F. L., and K.-M. Lau (2004), Trend and variability of China precipitation in spring and summer, Int. J. Climatol., 24, 1625-1644, doi: $10.1002 /$ joc. 1094 .

Yu, F. K. P. Price, J. Ellis, J. J. Feddema, and P. Shi (2004), Interannual variations of the grassland boundaries bordering the eastern edges of the Gobi Desert in central Asia, Int. J. Remote Sens., 25, 327-346, doi:10.1080/ 0143116031000084297.

Zeng, X., M. Barlage, C. Castro, and K. Fling (2010), Comparison of Land-Precipitation Coupling Strength Using Observations and Models, J. Hydrometeorol., 11, 979-994, doi:10.1175/2010JHM1226.1.

Zhang, X. Y., S. L. Gong, T. L. Zhao, R. Arimoto, Y. Q. Wang, and Z. J. Zhou (2003), Sources of Asian dust and role of climate change versus desertification in Asian dust emission, Geophys. Res. Lett., 30(24), 2272 , doi:10.1029/2003GL018206. 